\title{
A Note on Place-Names and Transliteration
}

The thorny issue of how to designate the names of places has not been easy to resolve consistently. The simplest solution would have been to use exclusively the contemporary name of the town or region with the exception of places like Kiev, Kraków, and Warsaw that have well-known and commonly used designations in English. There are, though, serious problems with this solution. Since this book is concerned primarily with the period before the partitions of Poland, I have designated places named in the text by their eighteenth-century names. The first time a place is mentioned, the contemporary name of the place is given in parentheses together, if appropriate, with other names. As a reference authority for contemporary place-names, I have relied on Merriam-Webster's Geographical Dictionary, 3 d ed. (200I). All the variants on place-names are found in the index. Modern place-names are used on the maps for the convenience of the reader.

I have used a highly simplified system of transliteration from Hebrew that is intended simply as a guide to pronunciation. The reader who knows Hebrew will be able to deduce what word is meant, while the reader who does not will be able to know how the word is pronounced. There are no dashes between articles and the words they modify. Only proper names are capitalized. 
This page intentionally left blank 